\title{
PRÉSTAMOS REMOTOS DEL SÁNSCRITO AL ESPAÑOL: EL COMERCIO DE PIEDRAS PRECIOSAS EN LA INDIA ANTIGUA
}

\author{
Remote loans words from Sanskrit to Spanish: \\ the trade of precious stones in Ancient India
}

Sol Argüello Scriba ${ }^{1}$

\begin{abstract}
RESUMEN
El estudio de los nombres de las piedras preciosas lleva consigo la investigación del comercio entre la India Antigua, Grecia y Roma, y con esta actividad, las transformaciones culturales. Términos como esmeralda, diamante y rubí tienen su origen en el sánscrito, porque es en esta lengua, donde se dan los primeros y más claros documentos que clasificaron estas gemas, y donde sus compositores, los brahmanes, tenían el control.
\end{abstract}

Palabras clave: comercio, esmeralda, diamante, rubí, India Antigua.

\begin{abstract}
The study of the names of precious stones carries with it the investigation of the trade between Ancient India, Greece and Rome, and with this activity, the cultural transformations. Terms like emerald, diamond and ruby have their origin in Sanskrit, because it is in this language that was given the earliest and clearest documents that classified these gems, where their composers, where the Brahmins who had the control.
\end{abstract}

Key Words: commerce, emerald, diamond, ruby, Ancient India.

\footnotetext{
${ }^{1}$ Universidad de Costa Rica. Profesora de la Escuela de Filología, Lingüística y Literatura. Costa Rica. Correo electrónico: solarcr1 @gmail.com
} 


\section{Introducción}

Para muchos occidentales, aún hoy, la India sigue siendo un subcontinente de contrastes, porque a pesar del crecimiento económico persiste una gran pobreza y, al mismo tiempo, se observan exuberantes riquezas. En la actualidad, permanecen tradiciones de larga data, lo que a los ojos occidentales se pueden considerar costumbres exóticas o extrañas, por ejemplo, al ver encantadores de serpientes, fakires y ascetas desnudos (Thapar, 2010, p. 1); y, recientemente, las películas de Hollywood. Imágenes plasmadas en Occidente y que se inician con las primeras narraciones en lengua griega de navegantes que llegaron a la India o que escucharon relatos sobre este subcontinente.

Esta visión se puede agrupar en tres aspectos: el primero, que habla de la riqueza por sus piedras preciosas, las especies, las telas y adornos; el segundo, el exotismo en sus seres fantásticos, animales, cosas, costumbres, usos extraños; y, por último, la sabiduría, que hace referencia a los ascetas o ermitaños indios con estilos vegetarianos de vida que a los griegos impresionó mucho (Tola y Dragonetti, 1982, p. 154).

Estas ideas sobre la India se comienzan a plasmar de manera legendaria y mítica en los escritos de navegantes que se aventuraban hacia lo desconocido, hacia el Este. Dentro de lo que se comerciaba están los metales, las especies, las piedras preciosas, animales. Como consecuencia, con la compra y venta llegaron términos, provenientes del sánscrito que, a su vez, pasaban a las lenguas habladas de la India (prákritos). Palabras que caminaron, por las rutas del comercio, al persa antiguo, al griego y al latín para convertirse en términos de nuestra lengua española; en otros casos, pasaron al árabe o al hebreo, y luego al español durante la larga estancia musulmana en España.

En la Antigüedad, hubo dos rutas de comercio: una por tierra y otra por mar, o por ambas: la denominada Ruta de la Seda. Ambas llegaban al Mediterráneo, tal como se lee en el Periplus maris Erythraei o el Periplo del mar Rojo, texto en griego que describía las rutas comerciales conocidas desde tiempos muy antiguos y cuya autoría va desde el siglo III al I a. C. El texto señalaba las rutas que iban desde los puertos en la India hasta el Mediterráneo y viceversa, las cuales, durante las épocas del Imperio romano, fueron muy importantes para el comercio de Roma con Asia. 
Cada palabra tiene una historia que contar; desde nuestro punto de vista occidental, se asumen el significado y el aporte a las lenguas modernas, por ello es valioso intentar dar una explicación de su uso dentro del contexto indio, y así comprender más sobre las posibilidades y su utilidad en el mundo antiguo, ya que son parte de la herencia cultural humana.

\section{Orígenes del comercio indio}

Durante el III milenio a. C., los antiguos habitantes de la Civilización del Valle del Indo, actual Pakistán, comerciaron con el Asia cercana, muchas veces con el intercambio de productos textiles y pedrería, tal como confirman los restos arqueológicos. El descubrimiento de esa civilización y su correspondiente estudio ha provocado la certeza de su contribución en la formación de la India posterior y, en la actualidad, se le considera un sustrato muy importante. Entre otras cosas, se observa en la forma de vestir de las personas hindúes, especialmente en el adorno con joyas de las mujeres indias de algunas regiones cuando se van a casar, como también en otros aspectos culturales que han sido parte de la cultura indoaria posterior, y parte de la India actual.

El intercambio y el comercio favorecieron la imaginación sobre la India, la cual se ha visto plasmada en la literatura en lengua griega a partir de los siglos V y VI a. C. En esta, se tiene noticia del escrito perdido de Esquilax atribuido al almirante griego Esquilax de Caryanda, quien, por encargo del rey persa Darío, viajó de las costas del Océano Índico hasta el Golfo Pérsico. El deseo de Darío era encontrar la ruta marítima que uniese la India con Egipto, destino y salida del comercio de ese momento. Y como había invadido algunos territorios del Noroeste de la India, especialmente la región de Gandhara que era parte de la Ruta de la Seda, buscaba también el dominio de las rutas marítimas comerciales para expandir el imperio persa. En Herodoto, Historias IV, 44, se lee un resumen del viaje de Esquilax.

Un contemporáneo de Esquilax, Hecateo de Mileto (nacido c. 560 y 550 a. C.) escribió un trabajo de carácter geográfico del cual solo se encuentran fragmentos. En este se emplean las palabras de origen persa (Argüello, 2012, pp. 39-44) para designar la India: Indoi, India e Indos y su derivado Indikos (frag. 310, 307, 311, 312 y 305). 
Posteriormente, Herodoto (n. 484 a. C.) en su obra Historias da una información bastante veraz, variada e interesante acerca de la India. Luego Ctesias de Nido, quien permaneció del 405 al 397 en la corte de Persia como médico de Artajerjes, escribió sus conocidas Indiká, en las cuales hay abundancia de información sobre una India llena de fantasía.

En su texto, Ctesias habla en varias ocasiones de la abundancia de gemas que se encontraban en riachuelos, así en el \#2 dice:

Habla sobre pantarba, un tipo de gema y como ésta arrastró pegadas unas a otras cuatrocientas setenta gemas y piedras preciosas que pertenecían a un mercader de Bactria, fueron arrojadas en el río, donde cayeron al fondo, todas juntas a esta piedra (Freese, 1920, p. 21). ${ }^{2}$

De la cita anterior, es posible extraer la palabra pantarba o pantarbe, la cual, según el diccionario de griego-inglés Liddell-Scott (1940), dice: pantárbe a precious stone, perhaps ruby. Y agrega los autores en los que se encuentra: Ctesias. Fr. 57.2, Philostr. V A3.46, Hld.8.11. Esta palabra se pretende explicar a partir del sánscrito, así pan-pant proviene de la raíz PAN: admirar (Monier-Williams, 1960, p. 152) y de arvatarvan (de la raíz $\mathrm{R}=\mathrm{ir}$ ): cochero (Monier-Williams, 1960, p. 28) o lo que lleva algo maravilloso. También el diccionario ofrece la raíz PAṆD, cuyo verbo en su forma del causativo es pandqayati, y el autor agrega que es un término inventado, pero que quiere decir juntar, apilar, tal como es descrita la piedra en el texto griego. Por otro lado, los términos arvāc, arvān: quieren decir que vienen juntos, de la raíz sánscrita $R=i r ;$ lo que indica que la palabra no es griega y tampoco es sánscrita porque no se encuentra la referencia literaria, probablemente pasó a un prácrito o sánscrito medio, lengua hablada, con la que se comerciaba.

Además, el texto habla claramente de la región de Bactria, situada al noroeste de la India, región que abarcaba la actual Pakistán, Afganistán, el sur de Uzbekistán, Tayikistán, lugares conocidos por los comerciantes que viajaban hasta llegar a Mesopotamia y Asia Menor. De ahí la referencia geográfica que confirma el comercio por tierra.

La actividad comercial entre la India y el Mediterráneo antes de Augusto fue enorme. La India comerciaba con Europa y el Medio Oriente y también con el Sudeste

\footnotetext{
${ }^{2}$ Traducción propia del original: "He says of the pantarba, a kind of seal-stone, that 477 seal-stones and other precious stones, belonging to a Bactrian merchant, which had been thrown into the river, were drawn up from the bottom, all clinging together, by this stone" (Freese, 1920, p. 21).
} 
Asiático y China; así la India servía de intermediaria para los productos chinos o de otras partes. Con esta actividad, varios aspectos culturales indios también emigraron, esto lo atestiguan diversos escritos en lengua sánscrita y fuentes no sánscritas. Se conoce de rutas marítimas y terrestres; a lo que Tola y Dragonetti agregan:

El comercio entre la India y Occidente ha debido existir desde una época muy antigua-desde varios siglos antes de Cristo. Este comercio se hacía por tierra y por mar. Intervenían en él comerciantes de numerosos países y razas. Existían ciudades y puertos donde las mercancías pasaban de unos comerciantes a otros, con el consecuente enriquecimiento de la localidad. El volumen de dinero que se manejaba en esas transacciones era muy grande (1982, pp. 197-198).

La llegada de Alejandro Magno (356-326 a. C.) al noroeste de la India, atravesando Persia, dejó a su paso gobernadores, quienes a su muerte en el 323 a. C. se declararon reyes de las respectivas provincias (Thapar, 2010, p. 42). Debido a su afición de hacer monedas, se ha podido reconstruir parte de la historia del momento. Sin embargo, entre el 200 a. C. al 300 d. C., la importancia del comercio se sitúa no en el noroeste de la India, sino en el sur, gracias a la epigrafía, la arqueología y la literatura en lengua Tamil, que a pesar de ser lengua dravidia, familia distinta de la indoeuropea, tomó los modelos sánscritos de composición literaria y brindó préstamos a la lengua sánscrita.

Es necesario comprender que las fuentes para toda actividad comercial en los reinados eran sánscritas, ya que quienes ejercían el control de los diversos reinos indios eran los brahmanes, para quienes su medio de comunicación era la lengua sánscrita, lo que se nota en la prolífica composición de manuales. De esta manera, la utilización del sánscrito para el comercio era indispensable y se nota en la variación fonética de la pronunciación de palabras sánscritas en los diversos prácritos y lenguas dravidias, como también al contrario: de los prácritos o lenguas no indoarias al sánscrito.

Los reinos de los Cholas, Pandyas, Keralaputras y Satiyaputras, entre otros, fueron grandes comerciantes y en sus textos hablan de un comercio floreciente con los Yavanas, o pueblos del Oeste de Asia. El término Yavana proviene del prácrito o las lenguas habladas Yona y se piensa que se refiere originalmente a los griegos jónicos; término que sirvió para denominar a cualquier pueblo comerciante del Oeste asiático, luego para los griegos y romanos, y siglos después para los árabes (Thapar, 2010, p. 44). 
Ya en la época del emperador Aśoka y la era Gupta, momento histórico que va desde el siglo IV a. C. al siglo VI d. C., la India se convirtió en un subcontinente de mucha riqueza, prosperidad y de influencia exterior. En gran medida se debió al incremento del comercio tanto por tierra como por mar a través de la conocida Ruta de la Seda desde China hasta el Mediterráneo, como también dentro de la India, hacia China y el Sudeste asiático.

La literatura sánscrita y la compuesta en las lenguas habladas, los prácritos, cuentan sobre ricos mercaderes, con vastos mercados tanto internos como externos a la India, como los textileros del Gandhara o de la región de Bengala producían telas que eran muy apreciadas en el resto de la India. Se sabe de la existencia de gremios de trabajadores de marfil, de piedras preciosas, metales, fabricantes de joyas. La exportación de diversos productos en grandes cantidades; lo mismo que la exportación de la seda importada de China y los caballos del centro de Asia que los indios comerciaban (Thapar, 2010, p. 47).

Entre las piedras preciosas se pueden citar, gracias a fuentes romanas de autores clásicos, las siguientes: diamantes, ónix, sardonix, ágata, sardio, cornerina, cristal, amatista, ópalo, beril, zafiro, rubí, turquesa, granate, esmeraldas, perlas y otras más. Y entre los frutos y especies: pimienta, nardo, canela, costus, cardamomo, jengibre, bálsamo, azúcar, aloes, índigo como colorante, algodón para vestidos, ébano para muebles, arroz, y diversas frutas cítricas, peras, damascos, que servían para fabricar perfumes, condimentos y otros productos. En cuanto a los animales: leones, tigres, rinocerontes, elefantes, serpientes para exhibiciones, perros y loros. También marfil y carey para adornos de todo tipo y seda china (Tola y Dragonetti, 1982, p. 224).

Roma también exportaba a la India entre otras cosas como coral, ciertas telas, papiro, vinos, dátiles, plomo, cobre, estaño, plata y oro, ámbar, joyas y piezas de alabastro, esclavos, entre otros (Tola y Dragonetti, 1982, p. 224).

Es también el momento histórico donde el comercio desarrolló rutas marítimas, utilizadas en menor escala en los siglos anteriores. Los barcos indios llegaban al Mediterráneo y vendían no solo productos indios sino también provenientes de varias partes de toda Asia. Hay puertos que se convierten en sitios de acopio, distribución y centros financieros, lo que provocó el crecimiento urbano de ciudades, cuyos reyes o emperadores invirtieron en la educación y en las artes en general y, por ello, no solo se 
enriquecían las clases altas, sino también se beneficiaban las diferentes clases sociales. Esto a pesar de que la división social y económica de castas se hace más firme y fuerte.

Con el comercio viajaron también las ideas, los brahmanes y los monjes budistas; los astrónomos indios descubrieron la existencia de la astronomía griega y romana, especialmente la que se realizaba en Alejandría. Además, los indios introdujeron el simbolismo de las piedras a los signos del zodiaco.

Siglos después, Marco Polo (s. XIII d. C. XV d. C.) siguió la ruta de las caravanas para fortalecer y renovar el comercio de Asia con Venecia, en su primer viaje; ya en el segundo viaje lo hizo por mar. Sus escritos entusiasmaron a Cristóbal Colón, quien deseoso de descubrir una nueva ruta hacia las Indias para traer especies y oro, y con el favor de Isabel la Católica, logró establecer no una ruta a la India, sino a un nuevo continente.

Por otro lado, en la India Antigua se encuentran dos factores que favorecieron la vida comercial y con este el desarrollo de una aplicación práctica y eficaz de la economía: el primero de ellos se refiere a la geografía que permitió el comercio por medio de las comunicaciones naturales del subcontinente. A la par de este, el desarrollo histórico. Ambos constituyeron un binomio inseparable, porque muchas veces la geografía favorece el conocimiento histórico y forma parte del escenario de los hechos en un momento determinado, tal como afirma Prakash-Charan $(1977$, p. 1) en su libro Foreign trade and Commerce in Ancient India, "la civilización es el producto de la interacción del ser humano y los factores naturales que favorecen a un país". ${ }^{3}$

Así, la India recibió diferentes pueblos gracias al comercio, la apertura y la aceptación, aunque esto último no implicaba la adopción de nuevas costumbres o tradiciones, más bien se dio en términos de tolerancia, porque para el indio estaba muy clara la distinción entre ellos y los pueblos que hablaban otras lenguas y que no practicaban el ritual védico, cuyo origen está en la pronunciación sin error de cada uno de los sonidos de cada palabra de los Himnos védicos.

El contacto con nómadas y comerciantes de fuera y dentro de la India se dio en todas las épocas, así desde las regiones de los Himalayas, las planicies de la región Indo-Gangética. Tanto por tierra como por los ríos, las rutas de las caravanas de

\footnotetext{
${ }^{3}$ Traducción propia del original: "Civilization is the product of the interplay of human and natural factors of the country concerned" (Prakash-Charan, 1977, p. 1).
} 
comerciantes se movieron por toda la India y fuera de esta; además de la presencia de grandes y extensos ríos navegables, lo cual favoreció el comercio.

Un segundo aspecto, producto del desarrollo histórico indio, se comprende a partir del desarrollo de los factores socio-políticos indios y de la formulación de una forma de vida individual y social. Para los hindúes la vida se concibe por medio de etapas, a esto se le ha llamado los Fines de la vida del ser humano, y esta división promueve el propósito de cada etapa de la vida del individuo y sus deberes, son los principios filosóficos, religiosos y sociales que se desarrollaron en la sociedad hindú, estos son: Artha, Kama, Dharma y Mokșa. Para la vida amorosa de la pareja está Kama; Dharma, para los deberes religiosos y morales; Mokșa implica la etapa de separación progresiva de lo mundano y la búsqueda de la liberación de la reencarnación; y Artha, el primero de los cuatro, cuyo objetivo es lo material, lo que se adquiere o se pierde.

Cada uno de estos fines fueron expuestos en distintos textos de composición oral: los śastras o libros de texto y los sutras para el estudio y comentario. Esta palabra proviene de la raíz ARTH (Monier-Williams, 2003, p. 90): obtener, desear, buscar; por esto, el significado del sustantivo es propósito, motivo, razón, riqueza, opulencia, dinero, negocios, asuntos legales, comercio, etc. Es la ciencia que abarca también todo lo referente al arte político, la administración del reino y en esta parte: el comercio, con todas las leyes de la compra, demanda, la forma de almacenar y demás.

Se ha manifestado que la literatura sánscrita ha sido conocida por sus textos religiosos y filosóficos más que por su visión práctica de la vida, lo cual induce a un grave error, ya que todos los fines de la vida tienen su manifestación en esta literatura.

El sistema más antiguo los reconoce de manera clara como partes del Dharma en un sentido amplio. Así, los Dharmasūtras tratan sobre los asuntos reales de las capitales y ciudades, oficiales, impuestos y preparaciones militares, y de cómo debe aplicarse la justicia. En lo que concierne a la épica, en el libro XII del Mahabharatha, aparece una lista de autoridades y autores de ellos, conocedores de la ciencia de los reyes, denominados rājaśāstra (raja: rey; śastra: manual); entre ellos están: Brihaspati, Vicālākșa, Uśanas, Manu, hijo de Pracetas, y Gauraśiras, quien también pasó por ser autoridad en el Dharma. De estas autoridades, solo se conocen sus nombres.

Por su lado, las doctrinas del Artha, literariamente, desarrollan la prosa y el verso didáctico, tienen carácter divino porque se le atribuye a Brahma la composición, quien, 
junto con otros dioses, participa de su composición. En el texto primero del Artha, el Arthasāstra menciona a Kautilīya como autor, sin embargo, nombra a Brihaspati, Bāhudantīputra, Vishālāksha y Uśanas como autoridades en la materia. En otro texto, el Kāmasūtra, se adscribe el Dharma a Manu; Artha a Brihaspati; y Kāma, a Nandin, como sus primeros creadores; muestra de su gran difusión e importancia.

Su composición no solo se adscribe a Kautilìya o Kautilya, (Keith, 1996, p. 51), también llamado Chānakya o Vishnugupta, quien fue ministro de Chandragupta Maurya, lo que situaría su composición en el siglo IV a. C.; pero esta fecha no puede aceptarse completamente, ya que la actual compilación no puede ser anterior al siglo III o IV d. C., aunque se conocen materiales más antiguos, y al parecer, vestigios de una versión asimilada. Se sabe que documentos anteriores son de calidad muy inferior.

El Arthaśāstra no tiene que ver con el deber religioso o moral, como lo es el Dharma, pero sí con los intereses reales. Más adelante va a ser llamado Nītiśāstra (de la raíz NI: conducir, guiar) o la ciencia de la conducta; también Rājanīti o conducta de los reyes y Dandanīti (de danda: castigo) o política del castigo. De modo que estas leyes con diferentes nombres indicaban la labor del rey: guiar por la fuerza del castigo al que desobedeciera su voluntad. Respetada por los poetas que vivían en las cortes, y en sus composiciones literarias se observa tal poder.

\section{Arthaśāstra: contenido y forma}

Es difícil que el original haya sobrevivido; posiblemente lo que se encuentre hoy sea el producto de recensiones posteriores. En Occidente, fue conocido en el año de 1909. El libro está dividido en 15 grandes secciones, llamadas Adhikaranas, y 180 subdivisiones, Adhyāyas, separadas por las máximas en verso que concluyen el texto en prosa; estilo que permite recordar o memorizar el asunto tratado en la prosa.

A continuación, se mencionará un resumen de los adhikaranas. En el I, se explica la educación del príncipe, el cual debía aprender sobre el Sāmkya, Yoga y el Lokāyata, y en religión: los Vedas y Vedāñgas. El Arthāśastra aceptaba la teoría brahmánica sobre las castas y sus deberes, sobre economía, agricultura, asuntos sobre el pastoreo de animales, el comercio, la industria y la política o Dandanīti. Los ministros del rey y su consejero son descritos junto con los diversos espías que le sirven para asegurar su 
gobierno desde todos los puntos de su reinado, incluyendo la princesa, que puede planear su muerte, hasta la gente de más baja condición; sus emisarios también son sus espías y embajadores, quienes lo mantendrán informado sobre todo lo que suceda a sus vecinos, especialmente.

Sus obligaciones son enumeradas, apareciendo su capacidad de oprimir. Su harem recibe especial atención y se hace énfasis en el peligro que puede correr cuando él lo visita, y se dan numerosos ejemplos de tipo histórico en donde se describen los asesinatos sufridos por reyes. Además, se enumeran los posibles peligros que puede sufrir el rey por calles o lugares públicos.

Entre los libros o apartados que componen el Arthaśastra, se encuentra el adhikarana XI o el Examen de las gemas que entran al tesoro real, en el cual se describen las joyas, piedras preciosas, cualidades, características, términos y lugares de proveniencia, todo con interés de dejar bien claro el "tesoro real". En el texto, se describen con mucho interés las perlas y los nombres de los collares de perlas están detallados, fueran o no de varias vueltas, incluso se clasifican los diamantes, otras piedras preciosas, animales, plantas y demás.

Posterior a la composición del Arthaśastra, se encuentran tratados que se refieren a distintas especializaciones, como la crianza de elefantes y, entre estos, encontramos una gran variedad de textos sobre la joyería en general, llamado Ratnaśāstra o Ratnaparīksha.

En esta obra, se le da importancia al factor geopolítico, ya que es un manual del siglo IV a.C., y en este se desarrollan los principios de la diplomacia o la teoría Mandala (círculos), y la ciencia económica; para esto explica las relaciones políticas, económicas y geográficas de un reinado.

En cuanto a la administración, el Arthaśāstra habla en un sentido literal de tres "vocaciones" con las que nace un individuo sea hindú o no, a partir del concepto más amplio de forma de vida: vṛtti y derivada de vārttā, que sostiene el tesoro y el ejército, abarca todo lo que el gobierno real recibe como los granos, el ganado, dinero y varios tipos de productos e implica tres ramas: la agricultura ( $k r s ̣ i)$, la ganadería (pāśupālya) y el comercio (vanijyā). Además, provee el dinero para la manutención de los trabajadores del estado (viști), así como también le da gran importancia al cuido de las viudas y huérfanos. En el momento de composición del texto, los artesanos y artistas no 
estaban incluidos en esta división del trabajo, pero debido al auge del comercio fueron integrados como parte del reino.

Es un manual que aconseja al rey cómo hacer a su reinado próspero y feliz, en el cual se prevengan las hambrunas, se proteja a los individuos indefensos, la eficacia administrativa y la jerarquía de valores. También hay un apartado para la protección de los agricultores y sus productos, la clasificación de los alimentos y a los mercaderes, además de la clasificación de las joyas, el oro y la plata y la creación de joyas. El manual especificaba reglas para diversos artículos, desde las flores, vegetales y frutas, lo mismo que para los diamantes, perlas y otras piedras preciosas.

Para los mercaderes que venían en caravanas, primero debían obtener el permiso en las fronteras del reino, donde sus productos debían ser sellados y estampados con el sello real, debían pagar impuestos y la seguridad para transitar tranquilamente por el reinado. Si los productos que traían competían con los de los habitantes del reino, se protegía a los vendedores nativos.

En cuanto a las rutas para los comerciantes, el Arthaśāstra difiere de otros manuales posteriores, pues recomienda las rutas terrestres y no tanto las marítimas; además, habla de que eran mejores las del Sur, lo que indica el gran desarrollo de esa zona en el comercio.

\section{Términos sánscritos que viajaron con el comercio: piedras preciosas}

\subsection{Esmeralda}

El diccionario de Coromines (2010, p. 227) dice que el lema esmeralda aparece con la marca de h. 1295 (como esmaragde h. 1250). Del latín smaragdus, m. o f., y este del gr. smáragdos, f. id. Derivado, Esmeraldino, 1640. Es en el siglo XIII, aparece en un escrito por primera vez en lengua española. Sin embargo, esa palabra a su vez proviene del término sánscrito marakatas. En latín, smaragdus, smaragdinus, adj: esmeraldino, tiene dos significados: una piedra preciosa transparente de color verde. $\mathrm{Y}$ es el nombre de esmeralda, berilo, jaspe y malaquita. Existen varias palabras relacionadas con la palabra sánscrita marakata: esmeralda, palabra que como adjetivo implica el color verde, estas son: 
Griego: smaragdos o máragdos

Acadio: barraqtu

Semita $b-r-g$ : brillante, que chispea

Hebreo bareqet: esmeralda

Árabe: zamant, barq que significa brillante

Sánscrito marakta, marakatas: esmeralda de la palabra marak: luz, brillo

Tamil: marakatam

Persa: zabargat, zamarat: corazón de piedra

Turco: zümrüd

Ruso antiguo: marokat: esmeralda

Hindi: smarak: monumento, epitafio, panteón

Francés antiguo: esmeralde

Latín clásico: smaragdus

Latín Medieval: esmaraldus

En cuanto a la palabra latina, es introducida en la literatura romana por Plinio el Viejo (23-79 d. C.) en su libro XXXVII, capítulo 16. Sobre las piedras, explica el color verde de la piedra igual al verde de la naturaleza, por eso provoca descanso. En el capítulo 17, continúa caracterizando las esmeraldas, donde habla de unos veinte tipos de estas, cita de dónde provienen las mejores esmeraldas, y no necesariamente de la India, sino del norte de Egipto, también de Escitia, pueblos de origen iranio, llamados por los romanos Sármatas.

Consideraba defectos de las esmeraldas: la falta de claridad y transparencia, al explicar estas razones cita otras piedras como la calcedonia, alabastro o el cuarzo, y los lugares de donde provienen. En realidad, emplea el término Smaragdites para hablar de estas supuestas esmeraldas defectuosas. Muy probablemente, se refiere a los llamados berilos, en los que se clasifica la esmeralda científicamente.

Los Berilos constituyen uno de los grupos más importantes de piedras. Su nombre en español proviene del latín: beryllus, préstamo del griego béryllos (Coromines, 2010, p. 73), en sánscrito védico es: virukmat (Rig Veda): brillante, 
esplendoroso, ornamento brillante; también el otro término virupa: de muchos colores, de diferente forma (Macdonell, 1979, p. 287). Incluso, se clasifican con los nombres de gomeda, gomedakah (Monier-Williams, 2003, p. 47), el primero de los términos literalmente significa: grasa de vaca, y es una gema que proviene de los Himalayas y del río Indo; se clasifican por su color en cuatro tipos: blanco, amarillo pálido, rojo y el azul oscuro (Monier-Williams, 2003, p. 366). Los primeros sitios de donde se sacaban las piedras para su comercio son Europa y Asia Cercana. Piedras clasificadas por su color en el Arthaśāstra.

Las variedades del Berilo -en cuanto a color y a variedad- se deben a su composición química de silicato de aluminio, las más comunes son:

1. Esmeralda: verde

2. Bixbita: rojo-grosella

3. Heliodoro: amarillo-oro

4. Rosterita: rosa (de Madagascar) o incoloro (de los Urales)

5. Aguamarina: verde-marino, de composición azul

6. Morganita: rosa

La palabra sánscrita marakata o marakta: esmeralda, proviene de la raíz MṚ: morir (Monier-Williams, 2003, p. 789); que da origen a mara: tierra, el mundo de los muertos, forma metafórica de hablar sobre la procedencia de la vida: la tierra, como también de clasificar las piedras como seres sin vida, no por su color verde, como se ha dicho en varios diccionarios y documentos sobre el origen de la palabra sánscrita. Muy probablemente esta palabra pasa a los prácritos o lenguas habladas y entra al vocabulario de otras lenguas, debido al comercio de las esmeraldas y otras piedras. Maraka es el nombre de un pueblo en la India antigua. Hay muchos más términos que sirven para designar la esmeralda en sánscrito que en otras lenguas modernas o clásicas. La clasificación y denominación se hace por color, forma, peso y demás, tal como se hace en la actualidad, pero de manera más simple. En este vocabulario, se aprecia la necesidad de clasificación de la piedra, especialmente por la intensidad del color o procedencia; en la mayoría de las veces, esos términos forman compuestos $\mathrm{y}$, curiosamente, algunos relacionan la esmeralda con el zafiro. 
Los nombres sánscritos para esmeralda son:

1. aśman, sustantivo masculino: piedra, piedra preciosa, cualquier instrumento hecho por una piedra, trueno, cielo. Tribu relacionada con la dureza de una piedra. En su forma compuesta es aśma: piedra y garbham o embrión de roca (Monier-Williams, 2003, p. 114). Tal como muchas veces se encuentran las esmeraldas.

2. harinmanih: esmeralda; de hari: amarillo y también verduzco. Mani: joya

3. gauhineyam

4. gārumat-mata: esmeralda que viene o está consagrado al pájaro Garuda, el vehículo del dios Visnu. También es una planta de antídoto contra los venenos, especialmente del veneno de las serpientes.

5. gāruḍa y garuḍāśmā: en el texto sobre las piedras preciosas, esmeralda.

6. garuḍāmani: usado por el gramático sánscrito Bāṇa en su obra Harṣacarita.

7. rajanīlah: el zafiro del rey.

8. munīlakah: de mu: color oscuro o pardo; nīlakah: azul oscuro, también zafiro.

9. masārah: es un zafiro y también una esmeralda.

10. apan̄ikah:apa de ap: agua y nīkah: nombre de un árbol. En su forma femenina es: canal de irrigación.

11. mārakatah, -ti, -tam: adjetivo: esmeraldino.

La abundancia de términos en lengua sánscrita, que describen la esmeralda, permiten pensar en dos aspectos: el gran comercio establecido de la India hacia Europa y los países asiáticos; por otro lado, la terminología fue creada a partir de la formación de palabras, de derivaciones y de metáforas, lo cual enriqueció el vocabulario de las lenguas habladas o prácritos. Pero, sobre todo, con la intención de enseñar a comerciar o reconocer el valor de las piedras. Los brahmanes fueron los compositores de los manuales que se refieren a las piedras: Rājanighaṇṭu y el Arthaśāstra.

Con el comercio, se desplazaron no solo la clase de los comerciantes, sino los brahmanes, especialistas en las gemas. Supervisaban la compra y venta de las joyas, tal como se aprecia en el capítulo XI del Arthaśāstra, titulado La revisión de las gemas que van a entrar al tesoro, trabajo que realizaba el brahmán superintendente, experto en 
gemas preciosas. Lo que permite comprobar que en el siglo IV a. C. el comercio fue una gran fuente de riqueza para los reinados indios, principalmente, por medio de la Ruta de la Seda, de larga data. Aún el comercio con Roma estaba distante; ya en épocas de Augusto el comercio con la India se empezó a desarrollar en gran medida.

Las distinciones que Plinio el Viejo hizo no son más que información recogida muy probablemente de los comerciantes árabes que por cercanía hablaban la lengua griega y, por ello, las palabras latinas tienen su origen griego, pero en realidad el comercio indio era recogido muchas veces por los árabes, ya fuese por tierra como por mar. Los árabes ejercían un monopolio, no permitían que los barcos indios llegaran al Mediterráneo (Tola y Dragonetti, 1982, p. 200); compraban las mercaderías indias y las que estos traían de otras partes de Asia y las vendían a los griegos, de ahí que el término latino smaragdus proviene del griego, pues los árabes debían comerciar en esa lengua y no en la suya. Lo que comprueba que los productos indios a veces se consideraban productos de Arabia.

Luego de establecido el comercio con Roma, se conocen varias embajadas enviadas por reyes indios ante los emperadores romanos; y en épocas de Augusto, los navegantes romanos dominaron los monzones y pudieron llegar a las costas del Sur de la India para comerciar, por ello se encuentran restos arqueológicos con monedas romanas en varios lugares en el subcontinente indio.

Entre los productos que exportaban a Occidente está el azúcar utilizado para la preparación de medicamentos, muselina, sedas (que India compraba a China para exportarlas a su vez), ébano, colorantes, marfil, piedras preciosas y perlas que eran desconocidas antes de Alejandro, la canela, la pimienta, animales y mujeres (Tola y Dragonetti, 1982, p. 201).

En cuanto al comercio de esmeraldas, este continuó en la Edad Media europea, aunque no $\tan$ floreciente. En 1520, se tiene la primera noticia de esmeraldas americanas en España, el galeón español Nuestra señora de Atocha que se hundió en 1622, en la costa de Florida, llevaba esmeraldas. La ruta de comercio de esmeraldas hacia Europa cambió, venía de América.

Pero en los siglos XVII y XVIII, el comercio de esmeraldas se intensificó de nuevo en la India. Recientemente, se conoce uno de los grandes tesoros encontrados en 
Turquía, en el palacio Topkapi Sarayi y en Marzaki, en el cual no solo se encontraron esmeraldas asiáticas (indias) sino también colombianas (Giuliani et al., 2000, p. 633).

La comercialización de esta piedra en la India actual la llevan a cabo los comerciantes de la religión jainista, quienes fueron contratados por reyes, especialmente de la región de Rajasthan, que era parte de la Ruta de la Seda. Desde el siglo XVIII, estos joyeros jainistas fueron escogidos por el maharaja de la región, precisamente, por sus principios religiosos, los cuales deben cumplir con cinco votos: Ahimsa o no violencia o alimentación estrictamente vegetariana; Satya o verdad y de ahí el no mentir en los negocios; Asetya o no robar en el negocio ni al dueño; Brahmacharya o castidad; y Aparigraha no apego a las cosas del mundo. La mayoría de sus gemas provienen de Zambia y Brasil. Las esmeraldas son compradas, cortadas y pulidas en cientos de tiendas en esta región de Jaipur.

Sin embargo, las esmeraldas fuera de la India no provienen de un mundo idealizado, sino más bien, son producto muchas veces de la violencia, del robo, de la estafa, del comercio sexual y del apego a las piedras de un verde brillante. Ante esta contradicción, los jainistas explican que no hay violencia en la importación, exportación o en el corte de las piedras, las piedras que llegan para ser trabajadas y comercializadas por ellos, lo cual no afecta su karma (recompensa por sus acciones). Afirman que la violencia está en la explotación de las minas, por ello buscan limpiar y purgar el karma con la honradez y honestidad en el negocio de las esmeraldas (Brazeal, 2013, p. 120).

\subsection{Diamante}

En español, el lema diamante, según Corominas, corresponde a lo siguiente:

me.s.XIII. Del latín vg. diamas,-antis, alteración del lat. adāmas, -antis, íd., y éste del gr. adámas, -antos, 'acero', 'diamante', derivado negativo del damáō 'yo domo, venzo', con el sentido primitivo de 'indomable, duro'.

Deriv. Diamantino, 1617; culto: adamantino (2010, p. 191).

Por su lado, Plinio el Viejo en el Libro XXXVII, capítulo 15, habla de los diamantes y sus seis variedades; y según el autor, es la más valiosa de todas las piedras, propia de los reyes, pues es la piedra más dura, capaz de rayar el cristal. Dentro de los lugares en donde se encuentran los diamantes nombra: las minas en Etiopía y repite que la mayor cantidad proviene de India. Emplea el término adamas. 
Los términos sánscritos para diamante son:

1. hīram: diamante; trueno

2. hīraka: diamante, se le relaciona con Śukra o Venus

3. hirarakārah: cortador de diamantes

4. vajrah: vaj: fuerte, poderoso: el dios Indra, rayo y rah de la raíz RAJ = ser brillante

5. varjraman: diamante, poderoso brillo

6. vajrākarah: mina de diamantes, que tiene la forma de un rayo

7. varārakam: de vara: el mejor y araka: arista

8. avikam: nombre del diamante de una rueda

9. aśiram: diamante que consume el sol

10. dadhīcyasthi: el trueno, diamante

11. dūdāghḍam

12. lohajit: conquistador del hierro, diamante

13. sūcīmukham

14. ralamirūpam

15. bhārgavapriyah: bhārgava: la divinidad de los Vedas y priyah: querido, devoto

16. aśinagrāvan: diamante

17. manīndra: el jefe de todas las gemas

En persa: almās, tamantriya: piedra encontrada en una mina de diamantes.

Ninguna de las palabras coincide con la palabra latina adamas, sin embargo, la raíz sánscrita DAM significa: domesticar, someter, domar, es la misma raíz de la palabra griega, tal como lo proponen Corominas y otros autores.

En cuanto a estas palabras que designan o definen al diamante como hīram, término que sirve para designar el trueno, la serpiente, el león, un cordón de perlas, también con Hāra, uno de los avatares de Śiva, quien tenía el trueno de Indra en el Hinduismo, ya que en época védica el rayo es característica de Indra, la divinidad principal de los Vedas. La característica de brillar como un rayo o trueno, de ser 
poderoso para destruir otros diamantes o piedras preciosas, está expuesto en los términos sánscritos, muy distinto del término en griego y en latín. En cuanto a la relación del dios Śiva, dios de los muertos, asimila al dios Prajapati el señor de las creaturas, encierra en sí la destrucción de todos los seres de la creación en su parte destructiva. El diamante es comparado con su poder (Bhattacharji, 1970, pp. 267-283).

En cuanto al Arthaśāstra (Libro XI, sobre la revisión de las gemas que entran al tesoro real), su autor dedica una larga explicación a los diamantes, la que sirve para aplicarse a las demás piedras preciosas. Habla de que el especialista o encargado de las piedras del tesoro real debe conocer el origen, la forma, el color, el tamaño y la cualidad de los diamantes, las piedras preciosas, perlas y los corales. Para ello, debe emplear expertos.

La proveniencia de estas piedras, según su autor, estaba en los asientos de los ríos y en las minas terrestres. Al hablar del diamante, lo define como vajrah (el rayo o el trueno) y lo llama el más valioso de todos. Seguidamente, el texto nombra diversos lugares, entre los que llama la atención está: Maṇimanta. Explica que existen unas minas en Manimantaka, y aclara que se encuentran cerca de la montaña Maniman o Manimanta, término que permitió aclarar que sus nombres en griego y en latín provenían de uno de los lugares de su explotación en la India; lo que permite determinar que era la región de dónde provenían los diamantes en la India y, así, relacionarla con el término griego para acero, y la relación entre el brillo, dureza y fortaleza de esta piedra que la diferencian de las otras piedras preciosas. De esta manera, por su resistencia al calor, la capacidad de rayar u horadar la superficie del vidrio, refractario de la luz, la piedra que tiene el mejor brillo, extrema dureza y que le permite ser capaz de cortar otro diamante. Cualidades descritas en el Arthaśastra (Libro XI) hicieron que se considerara similar al acero, de ahí el origen del término griego: adámas, adamantos: acero; y el adjetivo: adamantinos: de acero, duro como el acero. Términos que emplea también Plinio el Viejo $(37,18)$ cuando habla de los diamantes, cualidades y proveniencia, los introduce en el latín y, luego, en otras lenguas de origen romance como el español.

Es interesante también que el autor del Arthaśastra habla de las minas terrestres, sus características y de los cortadores de diamantes hirarakārah. En cuanto a sus colores, son denominados por él así: ojo de gato, la flor de Śīrīṣa, la flor de mūlātị, orina de vaca, la grasa de vaca, el cristal claro. 
Es considerada la piedra de los reyes. Además, se cree que existía un brahmán especializado en las gemas preciosas que entraban al palacio, aspectos que permiten comprender cómo desde antes del Arthaśāstra, en manuales anteriores de los siglos IIIIV-V a. C. ya existía esta especialización entre la clase sacerdotal, aparte de aquel otro grupo social de artesanos que hacían joyas y trabajaban los metales preciosos, los llamados vaiśyas.

Sumado a lo anterior, se encuentra el nombre Daimabad, región de las planicies del Deccán, caracterizada porque fue un sitio de comercio, de paso de migraciones y rutas comerciales, donde se han encontrado bronces de la época de la Civilización del Valle del Indio, Harappa y Mohenjo Daro, quienes por los restos arqueológicos encontrados se sabe que comerciaron con otros pueblos, inclusive con los jonios (Basham, 1989, pp. 352, 112).

\subsection{Zafiro}

Coromines señala acerca de esta palabra lo siguiente:

zafiro, princ. s.XVII, antiguamente çafir, 1335 (i çafil, h. 1290, çafi, 1250). Parece haberse tomado del ár. șafir íd. Aunque posteriormente sufrió el influjo del lat. sapphirus, tom. del gr. sáppheiros íd., que a su vez parece ser voz de origen oriental, emparentada con dicha palabra arábiga, Zafre 'óxido de cobalto empleado para dar color azul como el del zafiro’, 1817, del fr. safre íd., h.1200, que en último término endrá también del gr. sáppheiros.

DERIV. Zafirino, s. XVII; zafirina. Zafíreo (2010, p. 587).

En sánscrito, según Monier-Williams:

1. nīlah: oscuro, azul, zafiro

2. nīlakāntah: cuello azul, pavo real, zafiro

3. indranīla: indra: el dios védico Indra y nīla: azul

4. nīla-upalah: loto azul

5. nīlaśamāh: color azul

6. śani: es el planeta Saturno, el hijo del dios del Sol

7. śitiratna: de azul oscuro y ratna: joya

1. nīlamayah: adj. que contiene el azul de los lotos

2. nīlaguṇakah: adj. zafirino 
Es una piedra que desde épocas védicas (segundo milenio a. C.) se conoce. En la lengua pali, prácrito en que se compusieron los Jatakas, que cuentan las vidas anteriores del Buda, aparece el término indanīla, como préstamo del sánscrito.

En el Arthaśāstra, el sustantivo referente a zafiro viene en conjunto con otros términos formando compuestos, nunca solo, así por ejemplo: kalāyapuṣpaka o flor de color oscuro; mahānīla o muy azul; jāmbavābha o la fruta del jambu; jīmūtaprabhā o la luz de nube; mandaka o reaviva; śitavrștiti o lluvia fría; sūryakānta o favorito del sol.

En otras fuentes se encuentra el término indranīlaśīla como el color de Indra y en el Harșacarita la forma de mahānīla; y en el manual de las piedras preciosas el Rājanighanțu da dos características que significan color azul: nīlaśamāh y nīlopalah (nīla-upalah).

Pero ninguna de las anteriores da origen a la palabra zafiro en español o en sus correspondientes en griego y en latín. Sin embargo, zafiro proviene del sánscrito sphadikah que es cristal o cuarzo; también sphaț-ika, sustantivo masculino que es cristal, forma compuesta con maņi (joya) con el mismo significado; es un epíteto del Monte Kailasa; sphațikaşilā, sustantivo femenino para cristal (Macdonell, 1979, p. 367).

Como las composiciones de los textos sánscritos fueron orales durante siglos, la escritura comienza a utilizarse en época de Aśoka. Anteriormente, no se usó y muchos manuales como los de las piedras preciosas eran aprendidos y repetidos de memoria porque pertenecían a la clase administrativa y religiosa: los brahmanes, a los cuales no les interesaba popularizar el conocimiento. Sin embargo, parte de este conocimiento salió de la India, pues eran medios prácticos; en lengua latina, encontramos la obra de Plinio el Viejo, quien escribe las características de los diamantes de manera similar al Arthaśāstra, en alguna de sus versiones posteriores.

\section{Piedras preciosas y la astronomía/astrología}

En este largo y gran comercio de piedras preciosas, los indios adoptaron la astrología/astronomía de los griegos y los romanos, pero incluyeron las piedras, según estos, correspondientes a cada uno de los cuerpos celestes. Lo que demuestra, en gran medida, el intercambio de conocimientos que se daba con el comercio. Es notorio que 
los indios, con base en la observación, solo hablaron de seis planetas, el resto son fenómenos celestes. De esta manera, agruparon las piedras con los planetas:

Rubí al Sol

Perla a la Luna

Coral a Marte

Esmeralda a Mercurio

Topacio a Júpiter

Diamante a Venus

Zafiro a Saturno

Jacinto a Rāhu (eclipse)

Ojo de gato a Ketu (jefe de los cometas)

\section{Bibliografía}

Argüello, Sol. (2013). Del sánscrito al español. Préstamos remotos y adecuaciones. Káñina, Rev. Artes y Letras, Universidad de Costa Rica, XXXVI (Especial)(2), $39-44$.

Basham, Arthur. (1989). The wonder that was India. India: Published by Rupa \& Co.

Bhattacharji, Sukumari. (1970). The Indian Theogony. United States of America: Cambridge University Press.

Brazeal, Brian. (2012). Indian religions in the global Emerald trade: a photo essay. Visual Anthopology Review, 28(2), 120-132.

Coromines, Joan. (2010). Breve diccionario etimológico de la lengua castellana. España: Editorial Gredos.

Freese J.H. (1920). Photius'Excerpt of Ctesias'Indica. Recuperado de www.tertullian.org

Giuliani, Gaston et al. (2000). Oxygen, Isotopes and Emerald Trade Routes since Antiquity. Science, New Series, 287(5453), 631-633. 
Guralnik, David. (1978). Webster's New World Dictionary. U.S.A.: William Collins+World Publishing Co., Inc.

Keith, Berriedale. (1996). A History of Sanskrit Literature. New Delhi, India: Motilal Banarsidass Publishers.

Liddell, H.G. y Scott, R. (1940). Greek-English Lexicon. Oxford, Great Britain: Clarendon Press.

Macdonell, Arthur Anthony. (1979). A Practical Sanskrit Dictionary. Oxford, Great Britain: Cambridge at the University Press.

Monier-Williams, Sir Monier. (1960). A Sanskrit-English Dictionary. Cambridge at the University Press: Oxford, Great Britain.

Monier-Williams, Sir Monier. (2003). A English-Sanskrit Dictionary. New Delhi, India: Munshiram Manoharlal Publishers, Pvt Ltd.

Plinio el Viejo. Naturalis Historia. Perseus Digital Library. Recuperado de http://www.perseus.tufts.edu/hopper/

Prakash Charan, Prasad. (1977). Foreign trade an commerce in ancient India (vol. I-II). India, New Delhi: Abhinav Publications.

Thapar, Romila. (2010). Cultural Pasts. Essays in Early Indian History. New Delhi, India: Oxford India Paperbacks, Oxford University Press.

Tola, Fernando y Dragonetti, Carmen. (1982). Augusto y la India. Anales de Historia Antigua y Medieval XXII, (pp. 148-241). Argentina.

\section{(ब) $(\Theta \Theta$}

Esta obra está bajo una licencia de Creative Commons Reconocimiento-NoComercialSinObraDerivada 4.0 Internacional 